\title{
EDITORIAL
}

\section{The Next Generation of Connectivity in Family Medicine Research}

\author{
Mobammed A. Rasbid, MBCbB, MSc, MRCGP \\ Larry A. Green, $M D^{2}$ \\ 'University College London Medical School, London, United Kingdom \\ ${ }^{2}$ Department of Family Medicine, School of Medicine, University of Colorado Denver, Aurora, Colorado
}

Ann Fam Med 2019;17:291-292. https://doi.org/10.1370/afm.2426

$\mathrm{W}$ e live in a world that is more connected than it has ever been in human history, and although that connectivity brings with it opportunities for innovation and societal advancement, it also brings considerable challenges about security, privacy, and the sharing of false information and harmful ideas. In medicine, increased connectivity has been similarly double-edged. The Internet has helped foster greater community among the medical profession, with benefits in medical education, ${ }^{2}$ emergency preparedness, ${ }^{3}$ and the dissemination of new guidelines and evidence, ${ }^{4}$ but more negative outcomes, particularly related to breaching the traditional "boundary markers" of medicine, as well as liability and litigation, have also surfaced. ${ }^{5}$

Increased connectivity has influenced medical research, allowing cooperation among academics from across the world, providing a universal network that enables researchers from various locations and disciplines with diverse computers and operating systems to log data through a common interface.

This issue of the Annals includes a nationwide flashmob study for acute coronary syndrome by Schols and colleagues, ${ }^{6}$ whose methodology prompts consideration of a potentially important benefit of conducting clinical research in a connected world: time. In order to evaluate the Marburg Heart Scale as a clinical decision rule for family physicians to safely exclude acute coronary syndrome, Schols et al used a prospective observational

Conflicts of interest: authors report none.

\section{CORRESPONDING AUTHOR}

Mohammed A. Rashid

University College London Medical School

GF664 Royal Free Hospital

London NW3 2PF, United Kingdom

ahmed.rashid@ucl.ac.uk flash-mob study to collect data in relevant patients. Crucially, they mobilized $20 \%$ of the family physicians in the country (the Netherlands) and were thus able to collect the necessary data in just 2 weeks.

Time is important for a number of reasons. The ability to find answers to clinical research questions early has important ramifications for clinical practice and supports the most effective application of evidence-based medicine. In addition, such efficiency has the potential for significant cost savings when compared with traditional study designs, with benefits for clinicians, patients, families, health care institutions, and governments.

Family medicine may be a particularly good setting for the flash-mob design. With a physician and patient population that is more diverse and dispersed than many secondary care settings, the challenges of traditional methods may be easier to overcome using a more rapid and focused design. The key to understanding the extent to which this method can be used more broadly in family medicine research, though, lies in the approaches and mechanisms by which family physicians were mobilized to take part in this study. Indeed, this is both the biggest benefit and the biggest challenge of this study design, and will determine just how useful the approach may be in the long term.

Given that this was a novel research design, the authors used a variety of mechanisms to engage family physicians in their study, including individual family physicians and relevant organizations acting as "ambassadors" for the study and promoting it through both professional and social networks. Study information was also distributed via personal communications, publications, and a national family medicine conference, although it remains uncertain which of these really helped to achieve the dramatically high level of engagements. Were there, for example, key social media "influencers"? Was a "top-down" approach from 
national organizations more effective, or a "bottom-up" approach that involved personal networks of individual physicians? Further research examining this, perhaps using qualitative methodologies, would be valuable.

Sustainability and longevity are also important considerations when considering this research approach. The first of any study type can bring with it excitement and the novelty often helps to generate interest. It will be important to consider how personal and professional networks can be maintained and energized in the longer term, including how the process and bureaucracy can be best simplified, and whether or not there will be incentives for physicians or health care organizations to take part. This is particularly important given the high workload levels and rising prevalence of burnout in family physicians around the world. ${ }^{7}$

Most family physicians and family medicine researchers believe we should be able to better utilize technology and networking to produce clinical research that can improve the way we help patients. This belief has roots in the curiosity of individual family doctors like Will Pickles, James Mackenzie, John Fry, and Curtis Hames, whose work was scaled into practice-based research networks (PBRNs) in the last half of the 20th century and brought practices into collaborations to ask and answer questions that matter at the front lines of medicine. ${ }^{8,9}$ At first their technologies were entirely paper and pencil, mail, phones, and early word pro-

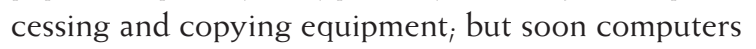
enabled the ambitions of the early primary care PBRNs, including combined networks across countries using digital, satellite-enabled connectivity. ${ }^{10,11}$ By the end of the century, PBRNs had established their legitimacy as important research laboratories, and they proliferated. ${ }^{12}$

The Schols et al paper in this issue of the Annals is consistent with the purpose and methods of PBRNs over decades. It focuses on a compelling question that, when answered, provides practical guidance for physicians making sense out of one of the most vexing problems people bring to family doctors - in this study, symptoms that might be an acute coronary event needing immediate attention. Data collection was constrained to a parsimonious data set and a short period of time that didn't burden the participating physicians. Physician judgement was allowed and compared with a structured tool, a recurring and particularly valuable focus of PBRN research. A steering committee provided leadership and organization, alignment of questions and methods, management of the study, oversight, and assurance of dissemination of results.

Consistent with the PBRN approach, the findings of the paper have real, tangible significance for family physicians. The fact that no patients with acute coronary syndromes were missed when the decision aid and clinical judgement were applied together is crucial information in the family medicine setting, where uncertainty and risk management are so crucial to practice. Importantly, these findings have been generated by family physicians, for family physicians, and have a clear focus on improving care.

The flash-mob study published in this issue of the Annals is a great example of innovation and ingenuity, harnessing the opportunities that exist in the connected world in which we live. Some questions remain unanswered, particularly about the optimal methods to form a movement and generate sustained interest to test ideas as regularly and effortlessly as needed in the fast-paced world of family medicine research. Further studies using this approach, and methodological research examining the factors linked to its successful implementation, would be welcomed. In years to come, it may mature into a powerful method for family physicians to drive clinical research forward and produce meaningful evidence that helps them provide the best possible care for their patients.

To read or post commentaries in response to this article, see it online at http://www.AnnFamMed.org/content/17/4/291.

Key words: social networking; health information exchange; data collection

Submitted May 3, 2019; accepted May 23, 2019.

\section{References}

1. Barlow JP. A declaration of the independence of cyberspace. Electronic Frontier Foundation. https://www.eff.org/cyberspace-independence.

2. Cheston CC, Flickinger TE, Chisolm MS. Social media use in medical education: a systematic review. Acad Med. 2013;88(6):893-901.

3. Merchant RM, Elmer S, Lurie N. Integrating social media into emergency-preparedness efforts. N Engl J Med. 2011;365(4):289-291.

4. Van Eperen L, Marincola FM. How scientists use social media to communicate their research. J Transl Med. 2011;9(1):199.

5. George DR, Rovniak LS, Kraschnewski JL. Dangers and opportunities for social media in medicine. Clin Obstet Gynecol. 2013;56(3): 453-462.

6. Schols AMR, et al. A nationwide flash-mob study for suspected acute coronary syndrome. Ann Fam Med. 2019;17(4):296-303.

7. Puffer JC, Knight HC, O'Neill TR, et al. Prevalence of burnout in board certified family physicians. J Am Board Fam Med. 2017;30(2): 125-126.

8. Green LA, Wood M, Becker L, et al. The Ambulatory Sentinel Practice Network: purpose, methods, and policies. J Fam Pract. 1984; 18(2):275-280.

9. Culpepper L, Froom J. The International Primary Care Network: purpose, methods, and policies. Fam Med. 1988;20(3):197-201.

10. Nelson EC, Green LA. The evolution of medical practice network computer systems: lessons from two regional projects. J Fam Pract. 1984;19(1):59-65

11. Froom J, Culpepper L, Grob P, et al. Diagnosis and antibiotic treatment of acute otitis media: report from International Primary Care Network. BMJ. 1990;300(6724):582-586.

12. Practice-Based research networks. Agency for Healthcare Research and Quality. https://pbrn.ahrq.gov/. 